\title{
The Discovery and Development of a Potent Antiviral Drug, Entecavir, for the Treatment of Chronic Hepatitis B
}

\author{
Hong Tang ${ }^{1}$, Jamie Griffin ${ }^{2}$, Steven Innaimo ${ }^{3}$, Lois Lehman-McKeeman ${ }^{3}$ and Cyril Llamoso ${ }^{3}$ \\ ${ }^{1}$ Bristol-Myers Squibb, Princeton, NJ, USA; ${ }^{2}$ Bristol-Myers Squibb, Paris, France; ${ }^{3}$ Bristol-Myers Squibb, Wallingford, NJ, USA
}

\begin{abstract}
Since the first approval of interferon for the treatment of chronic hepatitis B virus (HBV) infection in 1992, six additional antivirals have been developed: pegylated interferon-alfa2a, and the oral antivirals lamivudine, adefovir, telbivudine, entecavir and tenofovir. The availability of animal models for HBV infection and hepatocyte cell culture led to the discovery and development of oral antivirals targeted at HBV polymerase and reverse transcriptase, which inhibit viral replication. The discovery and development of entecavir, the first oral anti-HBV drug with both potent antiviral activity and a high genetic barrier to resistance, took more than 10 years before it was first approved in the USA. Since then, multiple real-life studies have provided data consistent with the findings of the registration trials and the long-term rollover study in terms of efficacy, resistance, and safety. Data from the long-term follow-up of patients enrolled in the registration studies showed that treatment with entecavir can lead to significant improvements in liver histopathology, and recent cohort studies have demonstrated that treatment with entecavir may reduce disease progression and the development of hepatocellular carcinoma (HCC) in patients with chronic hepatitis B. In addition, real-life studies suggest that entecavir may reduce $\mathrm{HCC}$ recurrence and increase survival rates in patients with HBV-related HCC post-surgical resection.
\end{abstract}

(C) 2013 The Second Affiliated Hospital of Chongqing Medical University. Published by XIA \& HE Publishing Ltd. All rights reserved.

\section{Introduction}

Worldwide, 2 billion people are infected with the hepatitis B virus and more than 350 million are currently living with chronic hepatitis $\mathrm{B}(\mathrm{CHB})$ infection. Liver cancer and other consequences of $\mathrm{CHB}$, such as cirrhosis and liver failure, cause about 600,000 deaths worldwide each year. ${ }^{1}$

Keywords: Entecavir; Chronic hepatitis B; Hepatitis B Virus; HBV DNA; Resistance; Discovery; Development.

Abbreviations: AUC, area under the curve; cccDNA, covalently closed circular DNA; CCR2, chemokine receptor $2 ;$ CHB, chronic hepatitis $B ; C_{\max }$, peak plasma concentration; $\mathrm{C}_{\text {trough, }}$ trough plasma concentration; CYP450, cytochrome $\mathrm{P}_{450}$; DHBV, duck hepatitis B virus; dNTP, deoxynucleotide triphosphate; ETV, entecavir; HBV, hepatitis B virus; HCC, hepatocellular carcinoma; HIV, human immunodeficiency virus; HSV, herpes simplex virus; LVD, lamivudine; PCR, polymerase chain reaction; RT, reverse transcriptase; WHV, woodchuck hepatitis virus.

Received: 13 March 2013; Revised: 15 May 2013; Accepted: 15 May 2013

DOI of original article: http://dx.doi.org/10.14218/JCTH.2013.00006.

Correspondence to: Hong Tang, Bristol-Myers Squibb, Princeton, NJ, USA.

Tel: +1- 609-897-2651, E-mail: hong.tang1@bms.com
Until the approval of interferon-alfa in 1991, there were no treatments available for $\mathrm{CHB}$ infection. Interferon is a biologic agent with both antiviral and immunomodulatory properties, and which is given by injection. However, its use is associated with safety and tolerability issues. ${ }^{2}$ The first oral antiviral, lamivudine, received US FDA approval for CHB in 1995. Approval for lamivudine was followed by that for adefovir in 2002. However, limited efficacy and the emergence of antiviral resistance proved to be a problem with both agents. ${ }^{3}$

Entecavir, an oral antiviral with both a potent antiviral effect and a high genetic barrier to antiviral resistance development, was approved by the FDA in the USA in 2005, followed by the healthcare regulators in Europe, Japan, China, and subsequently many other countries. It has now been approved in more than 70 countries worldwide, and is a first-line treatment choice recommended by all the major treatment guidelines for nucleoside-naive adult patients with $\mathrm{CHB} .{ }^{4-6}$

\section{Discovery}

On January 13, 1995, researchers from Bristol-Myers Squibb (BMS) discovered a compound showing a high potency against HBV, more potent than any previously tested drug. Investigated earlier for herpes simplex virus (HSV), the development of the compound, designated SQ-34676, had been left dormant because it showed little efficacy against HSV. However, when the compound was screened for antiviral activity against HBV, a new purpose was found. The compound was then developed as an antiviral for $\mathrm{CHB}$, and became known as BMS 200475, and later, as entecavir.

BMS has investigated nucleoside analogs as antiviral treatments for infections such as HSV, human immunodeficiency virus (HIV), HBV, and more recently, hepatitis $\mathrm{C}$ virus. The initial focus was to design alternatives to the $2^{\prime}$ deoxyribose portion of the natural nucleosides. It so happened that most of the alternatives to the ribose moiety were inactive compounds. However, placing nucleobases such as guanine and pseudo- $4^{\prime}-\mathrm{CH}_{2} \mathrm{OH}$ in positions similar to those found in lobucavir led to the discovery of entecavir (Fig. 1), which demonstrated potent HBV inhibitory activity with a half maximal effective concentration $\left(\mathrm{EC}_{50}\right)$ of $0.003 \mathrm{umol} / \mathrm{L}^{7-8}$

\section{Preclinical development}

Entecavir, like other members of the nucleoside analog class, is activated by intracellular phosphorylation, competes with naturally occurring nucleotides for utilization by the viral polymerase, and halts the synthesis of viral DNA. However, such a mechanism of action also confers the potential to 


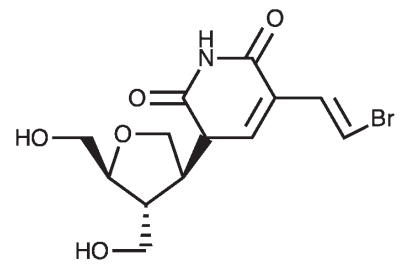

1: VZV and HSV

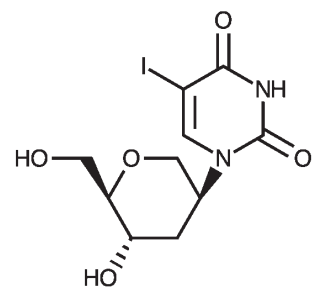

2: HSV

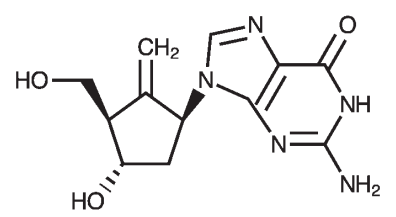

Entecavir: HBV

Fig. 1. Novel nucleoside analogs discovered at Bristol-Myers Squibb. *Nucleoside analogs showing activity against varicella zoster virus (VZV) and herpes simplex virus (HSV).

interfere with human genomic or non-genomic (mitochondrial) DNA replication.

Potential effects on mitochondrial function, investigated using primer extension assays, showed that entecavir does not inhibit mitochondrial DNA polymerase $\gamma$, and that the polymerase exhibits a strong preference for the natural substrate deoxyguanosine triphosphate, even in the presence of high concentrations of entecavir. In HepG2 cells, no effects on mitochondrial DNA levels or on the production of key mitochondrial proteins were observed. Collectively, these results suggest that entecavir has little or no potential for mitochondrial toxicity. ${ }^{9-10}$

Extensive in vivo evaluations to assess potential toxicity were conducted in mice, rats, dogs, and monkeys. In lifetime carcinogenicity studies, mice were administered entecavir at doses of up to 75 times (for the $0.5 \mathrm{mg}$ dose) and 42 times (for the $1.0 \mathrm{mg}$ dose) the doses used for human clinical exposures. Male rats were exposed to entecavir at levels of up to 62 times ( $0.5 \mathrm{mg}$ dose) and 35 times ( $1.0 \mathrm{mg}$ dose) human clinical exposures, while female rats were exposed to levels up to 43 times $(0.5 \mathrm{mg})$ and 24 times $(1.0 \mathrm{mg})$ human clinical exposures.

In some of those carcinogenicity studies, increased incidences of tumors were observed. These tumors presented in two major distinct patterns: lung tumors that were limited to mice and high-dose tumors in both mice and rats. Lung tumors in mice occurred at low exposure multiples (five times and three times the human exposure for the $0.5 \mathrm{mg}$ and $1.0 \mathrm{mg}$ dose, respectively) and resulted from early preneoplastic changes in the lung that were not observed in any other species. All other tumors were seen only at higher exposures. For these high dose-induced tumors, there were no pre-neoplastic or other relevant histopathologic changes observed in the affected tissues.

Genetic toxicology tests showed that, as expected for a nucleoside analog, entecavir was clastogenic in human lymphocytes at high cytotoxic concentrations (10,000 times higher than the $\mathrm{EC}_{50}$ for HBV in human liver HepG2 cells). However, it was negative in all other tests, suggesting that tumor findings in rodents following lifetime exposure to entecavir did not result from direct DNA damage.

The basis for the increased incidence of lung tumors in mice was investigated, and the findings showed that the tumors arose from sustained proliferation of type II pneumocytes. Of note, the strain of mice used in the studies (CD1) has been reported to have a genetic predisposition to the spontaneous development of lung tumors that are thought to arise primarily from type II pneumocytes. Entecavir induced hyperplasia of type II pneumocytes in the absence of cytotoxicity. A novel mechanism involving recruitment of alveolar macrophages into the mouse lung - a chemotactic effect on mouse monocytes mediated by chemokine receptor 2 (CCR2) - was directly associated with and shown to be required for proliferation of type II pneumocytes. Additionally, the entecavir-induced changes observed in mouse lung were species-specific. No lung tumors were noted in rat carcinogenicity studies, and entecavir was found not to be a potent chemoattractant for rat macrophages. Monkeys administered entecavir at doses $\geqslant 100$ times the human exposure at the $1.0 \mathrm{mg}$ dose daily for 1 year showed no histopathologic changes in the lung. Most importantly, studies showed that entecavir is not chemotactic for human monocytes even at concentrations as high as 6,000 nmol/L. Overall, recruitment of macrophages into the mouse lung is required for tumor development in mice, is specific to mice, and is not predictive of a similar effect in other species, including humans. Interspecies differences in CCR2 receptors appear to determine differences in the chemotactic activity of entecavir across species.

Tumors at sites other than the mouse lung, observed only at the highest evaluated doses of entecavir, were not associated with early histopathologic changes. A possible mechanism behind the development of these tumors is the potential of entecavir to perturbing intracellular deoxynucleotide triphosphate (dNTP) pools. Because entecavir is a nucleoside analog requiring phosphorylation for antiviral activity, extremely high concentrations might result in imbalances in dNTP pools. It is generally recognized that balanced pools of dNTPs (dATP, dGTP, dCTP, and dTTP) are essential for DNA synthesis and repair, and perturbations in dNTP pools are associated with various adverse effects, including tumor promotion.

In vivo studies showed that severe dNTP pool imbalances in hepatocytes isolated from mice and rats administered entecavir arose only at doses at which liver tumors were observed ( $4 \mathrm{mg} / \mathrm{kg}$ for mice, $2.6 \mathrm{mg} / \mathrm{kg}$ for rats). Levels of dGTP were decreased and dATP increased. Further studies with entecavir showed that the carcinogenic doses in rodents were associated with entecavir triphosphate concentrations exceeding $300 \mathrm{nmol} / \mathrm{L}$ in hepatocytes. Thus, it appears that the tumors observed at high doses of entecavir may result from dNTP pool disruptions that occur once a critical level of entecavir triphosphate is reached, and the fidelity of DNA replication and repair is impaired. The requirement for a threshold level for dNTP pool perturbation correlates with the observation that all entecavir-induced tumors were observed only at the highest doses tested.

Overall, the investigations into the rodent tumor findings from pre-clinical carcinogenicity testing of entecavir showed that the observed tumors in rodents are unlikely to be relevant to human safety. Indeed, to date, no increase in human malignancies associated with entecavir (or any nucleoside) has been observed in clinical trials or post-marketing studies. 
Several animal models were utilized to test the compound for antiviral efficacy. Research at the time, suggested that woodchucks chronically infected with woodchuck hepatitis virus (WHV) would be a good model for studying HBV antiviral agents. However, few pharmaceutical companies had used the model for such evaluations.

An initial dose-ranging study in woodchucks chronically infected with WHV found that 0.1 and $0.5 \mathrm{mg} / \mathrm{kg} /$ day of entecavir reduced circulating WHV DNA by $3 \log _{10}$ at week 4 . Subsequent testing using a more sensitive PCR method revealed that entecavir $0.1 \mathrm{mg} / \mathrm{kg} /$ day achieved a $7 \log _{10}$ reduction in serum WHV DNA to undetectable levels within 4 weeks in all animals. Compared with lamivudine, entecavirtreated animals had significantly greater reduction in hepatic covalently closed circular DNA after 4 weeks of entecavir therapy, with virus in several animals reaching undetectable levels over the course of 12 weeks of treatment. ${ }^{10}$

The results of these studies triggered great interest in the drug. A long-term study in woodchucks was conducted, in which entecavir $0.5 \mathrm{mg} / \mathrm{kg} /$ day was given daily for 8 weeks, followed by an off-treatment period in one group. This was compared to groups treated with a weekly dose of $0.5 \mathrm{mg} / \mathrm{kg} /$ day for 12 months (total treatment: 14 months) or for 28 months (total treatment: 36 months). Within 1-8 weeks, the virus rebounded in the animals withdrawn from the initial 8 weeks of treatment. However, 36 months of therapy achieved sustained viral suppression through the end of the study (5 months off therapy). In addition, entecavir therapy greatly improved the incidence of HCC and survival time compared with historic controls. ${ }^{11-12}$ Similar results were observed in the duck hepatitis B virus (DHBV)-infected Pekin duck model. ${ }^{13-15}$ In the transgenic mouse model, entecavir given at various doses from 0.0032 to $3.2 \mathrm{mg} / \mathrm{kg} /$ day for 10 days resulted in a significant reduction in hepatic HBV DNA, whereas expression of HBV proteins from the transgene was not affected. ${ }^{16}$

In reproductive toxicology studies, animals were given entecavir at dosages up to $30 \mathrm{mg} / \mathrm{kg}$ for $\geqslant 4$ weeks; no evidence of impaired fertility was observed in either male or female rats at exposures greater than 90 times those seen in humans at the highest recommended dose of $1 \mathrm{mg} /$ day. In rodents and dogs, seminiferous tubular degeneration was observed at exposures $\geqslant 35$ times those achieved in humans. In monkeys, no testicular changes were evident. ${ }^{9}$

\section{Clinical development}

The encouraging results from the pre-clinical studies helped the program to move into clinical development. After phase I-II studies from the late 1990s, phase III studies began in late 2001.

\section{Phase I safety and efficacy}

A few phase I single and multiple dose-ranging pharmacokinetic studies were conducted in subjects with or without CHB, and in subjects with hepatic or renal impairment. These studies demonstrated that entecavir was absorbed rapidly with peak plasma concentration $\left(\mathrm{C}_{\max }\right)$ occurring between 0.5 and 1.5 hours after oral dosing. ${ }^{17}$ With $6-10$ days of oncedaily oral administration, a steady state was achieved. The $\mathrm{C}_{\max }$ and area under the curve (AUC) increased in proportion to the dose. For the $0.5 \mathrm{mg}$ and $1 \mathrm{mg}$ oral dose, the $\mathrm{C}_{\max }$ at steady state levels were $4.2 \mathrm{ng} / \mathrm{mL}$ and $8.2 \mathrm{ng} / \mathrm{mL}$ respectively, while the trough plasma concentrations ( $C_{\text {trough }}$ ) were $0.3 \mathrm{ng} / \mathrm{mL}$ and $0.5 \mathrm{ng} / \mathrm{mL}$, respectively. ${ }^{9,17-18}$ The bioavailability of the tablet was $100 \%$ relative to the oral solution in healthy subjects. Food delayed the absorption of entecavir by $0.25-0.75$ hours, and decreased $C_{\max }$ by $44-$ $46 \%$, and AUC by $18-20 \%$. The estimated apparent volume of distribution was 4,000-8,000 L, which is in excess of the total body water, suggesting that entecavir is extensively distributed in the tissues. ${ }^{9,18}$ Binding of entecavir to human plasma proteins in vitro was approximately $13 \%$.

Early studies showed that entecavir is not a substrate, inhibitor, or inducer of the cytochrome $\mathrm{P}_{450}$ (CYP450) enzyme system. ${ }^{20}$ In drug-drug interaction studies, the steady-state pharmacokinetics of entecavir co-administered with lamivudine, adefovir, or tenofovir were not altered. ${ }^{19}$ Similarly, entecavir pharmacokinetics were not altered in patients with HIV-HBV co-infection who received entecavir in addition to highly active antiretroviral therapy. ${ }^{20}$

Entecavir is eliminated predominately by the kidneys with $62-73 \%$ of the administered dose recovered unchanged from urine in healthy subjects. ${ }^{17}$ Studies of renal clearance suggested that entecavir undergoes both glomerular filtration and net tubular secretion. The renal clearance of entecavir is independent of dose, and ranges from 360 to $471 \mathrm{~mL} /$ min. ${ }^{9,18}$ Entecavir has a long terminal elimination half-life of approximately 128-149 hours. With once-daily dosing, the observed drug accumulation index is approximately two-fold, suggesting an effective accumulation half-life of approximately 24 hours, allowing for once-daily administration of the approved doses. ${ }^{17}$

In special populations, reduced renal function leads to the accumulation of entecavir. Therefore, dose adjustment is recommended for all patients with creatinine clearances $<50 \mathrm{~mL} / \mathrm{min}$. However, in patients with hepatic impairment, no dose adjustment is required. ${ }^{21}$ In elderly subjects $(\geqslant 65$ years old), the entecavir AUC was increased by $29 \%$ compared with younger subjects (18-40 years old). This is probably due to differences in renal function. ${ }^{22}$ Therefore, the entecavir dose should be adjusted according to renal creatinine clearance. ${ }^{9,18}$ There are no significant entecavir pharmacokinetic differences related to gender or race. ${ }^{9,18}$

\section{Phase II-III efficacy and safety}

The efficacy and safety of entecavir for the treatment of adult CHB was assessed in several randomized, double-blind, worldwide phase II and III clinical trials in both nucleosidenaive and lamivudine-refractory patients. Separate registration studies were conducted in Japan and China.

Phase II dose-ranging studies were conducted in both naive $(0.1$ and $0.5 \mathrm{mg})$ and lamivudine-refractory (0.5 and $1.0 \mathrm{mg}$ ) patients comparing entecavir with lamivudine (100 mg) for 24weeks. Lamivudine-refractory patients were defined as those who remained viremic after at least 24 weeks of lamivudine therapy, or had documented lamivudineresistance substitutions. In both naive and lamivudinerefractory patients, daily treatment with entecavir was superior to lamivudine in reducing HBV DNA at weeks 22 and $24 .{ }^{23-24}$ In naive $\mathrm{CHB}$ patients, $0.5 \mathrm{mg}$ entecavir was superior to $0.1 \mathrm{mg}$ in reducing HBV DNA, ${ }^{25}$ while in lamivudine-refractory patients, $1.0 \mathrm{mg}$ entecavir was superior to $0.5 \mathrm{mg}$ in HBV DNA reduction. ${ }^{24}$

In AI463022, a phase III study with 709 nucleoside-naïve, hepatitis $\mathrm{B}$ e antigen ( $\mathrm{HBeAg}$ )-positive patients with $\mathrm{CHB}$ with 
Tang H. et al: The discovery and development of entecavir

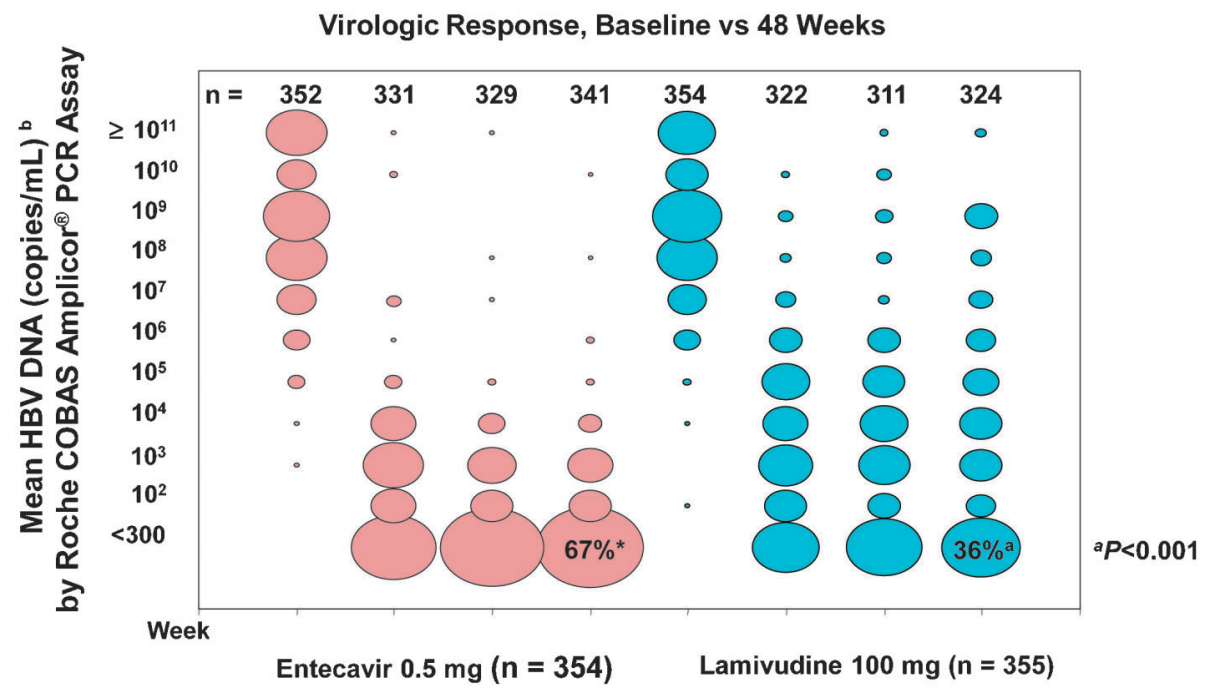

Fig. 2. Proportion of hepatitis Be antigen (HBeAg)-positive patients with undetectable hepatitis B virus (HBV) DNA ( $<300$ copies/mL) at 48 weeks. $\mathrm{NC}=$ non-completer, i.e. failure $[\mathrm{NC}=\mathrm{F}]$ in analysis.

high baseline HBV DNA (mean HBV DNA: $9.66 \log _{10}$ copies/ $\mathrm{mL}$ ) and elevated alanine amino transferase (ALT) (mean ALT: $143 \mathrm{U} / \mathrm{L}$ ), entecavir was superior to lamivudine for the primary endpoint of histologic improvement $(p<0.001)$ at Week 48. Entecavir was also superior to lamivudine for mean HBV DNA reduction ( -6.9 vs $-5.4 \log _{10}$ copies $/ \mathrm{mL}$; $\mathrm{p}<0.001$ ), proportion of patients with HBV DNA $<300$ copies/mL by PCR assay (67\% vs $36 \% ; \mathrm{p}<0.001$, Fig. 2 ) and ALT normalization (68\% vs $60 \% ; p<0.001) .{ }^{26}$ The $\mathrm{HBeAg}$ seroconversion rate was $21 \%$ among the entecavirtreated patients vs $18 \%$ in those treated with lamivudine. The safety profile of entecavir was similar to lamivudine. For patients treated in Year 2, the cumulative confirmed proportions of patients with HBV DNA $<300$ copies/mL and ALT normalization were $80 \%$ and $87 \%$ for entecavir-treated patients compared with $39 \%$ and $79 \%$ for lamivudinetreated patients, respectively $(p<0.001$ and $p=0.0056$, respectively). The cumulative rates of $\mathrm{HBeAg}$ seroconversion and hepatitis B surface antigen ( $\mathrm{HBsAg}$ ) loss were $31 \%$ and $5 \%$ for entecavir, and $25 \%$ and $3 \%$, respectively for lamivudine (Fig. 3). ${ }^{27}$

A phase III study AI463027 evaluated 638 nucleosidenaive, $\mathrm{HBeAg}$-negative patients with $\mathrm{CHB}$ treated with either entecavir or lamivudine. Histologic improvement after 48 weeks of treatment occurred in $70 \%$ and $60 \%$ of entecavirtreated and lamivudine-treated patients, respectively $(p=0.01){ }^{28}$ The mean HBV DNA reduction was $-5.0 \log _{10}$ copies for patients treated with entecavir, and $-4.5 \log _{10}$ copies for lamivudine $(p<0.001)$. For entecavir-treated and lamivudine-treated patients, the proportions of patients achieving HBV DNA levels of $<300$ copies $/ \mathrm{mL}$ were $90 \%$ and $72 \%$, respectively $(p<0.001$, Fig. 4$)$, and the proportions achieving ALT normalization were $78 \%$ and $71 \%(p=0.045)$. Safety profiles were comparable between the entecavir and lamivudine arms. Because of the study design, only a small number of patients continued blinded treatment in the second year.

In lamivudine-refractory patients, a phase III randomized controlled study of entecavir $1.0 \mathrm{mg}$ vs continued lamivudine $100 \mathrm{mg}$ daily demonstrated superior histologic, virologic, and biochemical response in entecavir-treated patients at Week $48 .^{29}$ Mean HBV DNA reduction from baseline was -5.11 $\log _{10}$ copies/mL for entecavir-treated patients compared with $-0.48 \log _{10}$ copies/mL for lamivudine-treated patients $(p<0.0001)$. HBeAg seroconversion was achieved by $11 \%$ of entecavir-treated patients and $4 \%$ of lamivudine-treated patients. The safety profiles of entecavir and lamivudine in this lamivudine-refractory population were comparable.

All patients from entecavir phase III studies were eligible for enrollment into a long-term rollover study in which they received entecavir $1.0 \mathrm{mg}$ once daily for up to 7 years. After 5 years of entecavir therapy, $94 \%$ of patients achieved HBV DNA levels of $<300$ copies/mL by PCR assay, and $80 \%$ had ALT $<1 \times$ the upper limit of normal (ULN.) ${ }^{30}$ The safety profile of entecavir in this long-term cohort study was consistent with the results of the phase III trials. In a cohort of patients who underwent liver biopsy in the rollover study, there was

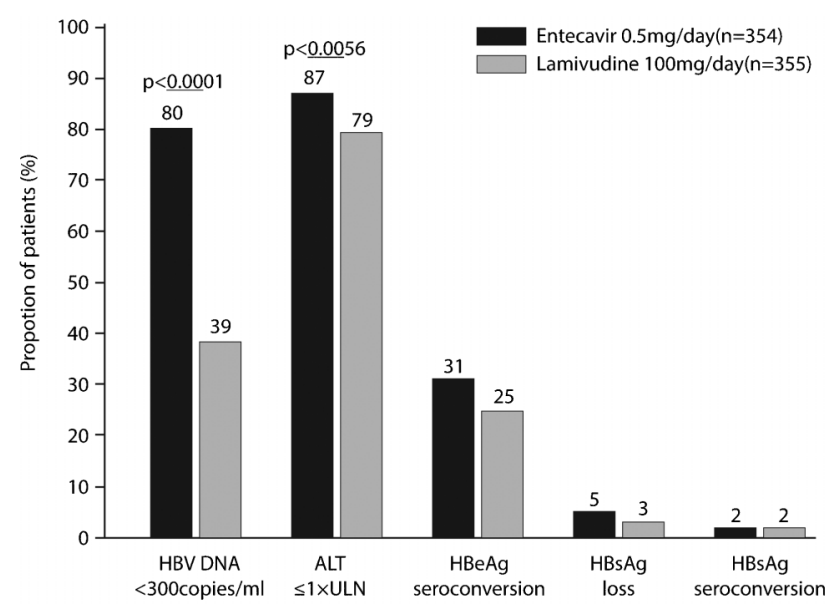

Fig. 3. Cumulative confirmed proportions of all treated patients who achieved undetectable levels of hepatitis B virus (HBV) DNA, normalization of serum alanine aminotransferase (ALT), or a serologic end point through 96 weeks of treatment. $\mathrm{HBeAg}$, hepatis B e antigen; HBsAg, hepatis B surface antigen; ULN, upper limit of normal. 
Tang H. et al: The discovery and development of entecavir

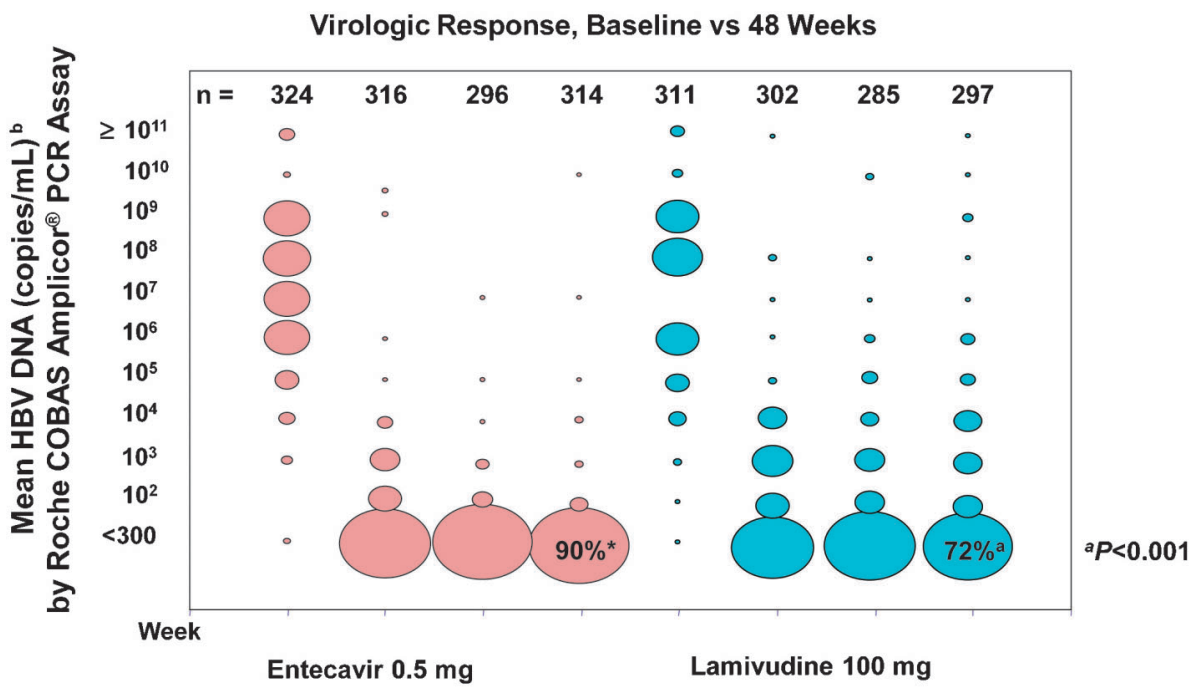

Fig. 4. Proportion of hepatis Be antigen (HBeAg-negative patients with undetectable hepatitis B virus (HBV) DNA ( $<300$ copies/mL) at 48 weeks. $\mathrm{NC}=$ non-completer, i.e. failure $[\mathrm{NC}=\mathrm{F}]$ in analysis.

improvement of necroinflammation in $96 \%$ of patients and improvement in Ishak fibrosis scores in $88 \%$ of patients (Fig. 5). Ten patients with advanced fibrosis or cirrhosis (Ishak fibrosis score 4-6) at baseline all showed improvement in Ishak fibrosis score. ${ }^{31}$ Safety analysis of more than 1000 patients in the long-term rollover study demonstrated that entecavir is well tolerated, with $\leqslant 5 \%$ adverse events potentially associated with the nucleoside/nucleotide analog. ${ }^{32}$ There were 12 patients with confirmed creatinine increases $>0.5 \mathrm{mg} / \mathrm{dL}$. Of these, 10 had at least one known renal risk factor: 5 patients had diabetes mellitus, 4 had hypertension, 2 had glomerulonephritis, 1 had metastatic

Histologic Improvement ${ }^{\star}$

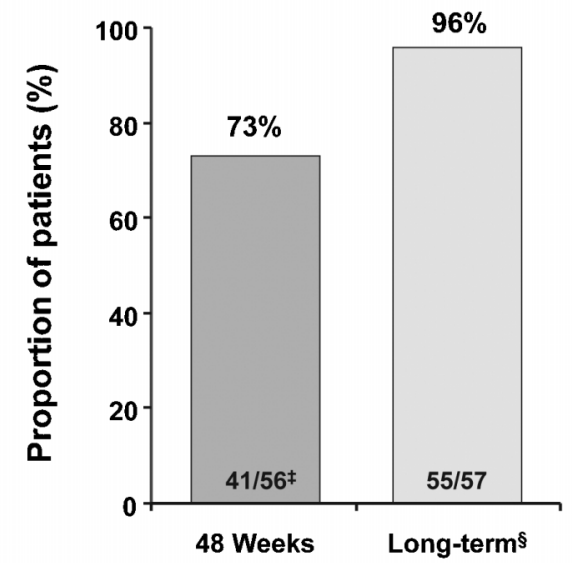

gastric carcinoma with ureteral obstruction, and 1 had decompensated cirrhosis with sepsis. In two patients with no known risk factors, the increase in creatinine was transient, with follow-up values returning to within normal ranges. The renal safety results of entecavir observed in the long-term rollover study are consistent with the observations in the phase III studies (only $1 \%$ of patients had increase in serum creatinine). No cases of lactic acidosis were observed. A similar safety profile for entecavir was observed in HIVHBV co-infected patients in study AI463038 in the placebo arm and in non-HIV infected subjects; there were no cases of lactic acidosis. ${ }^{9}$ In China, phase III studies demonstrated

\section{Improvement in Ishak fibrosis score ${ }^{\dagger}$}

\footnotetext{
* $\geq 2$-point decrease in Knodell necroinflammatory score and no worsening of Knodell fibrosis score compared with baseline $\dagger \geq 1$-point decrease $\ddagger$ One patient had an inadequate Week 48 biopsy $\S$ Median time of long-term biopsy: 280 weeks
}

Fig. 5. Improvement in histology and in Ishak fibrosis scores with long-term entecavir treatment. 
similar results to those observed in the global registration studies in both nucleoside-naive and lamivudine-refractory patients. ${ }^{33-35}$ In Japan, similar efficacy and safety results were observed to those in the global studies from three phase II bridging studies in nucleoside-naive and lamivudinerefractory patients. ${ }^{25,36-37}$ In the Japanese long-term rollover study, patients who received 0.5 or $1.0 \mathrm{mg}$ in the phase II studies continued the same dosage schedules depending on whether they entered from nucleoside-naive or lamivudine-refractory studies. Of the 58 nucleoside-naive patients who received 3 years of entecavir therapy at a dose of $0.5 \mathrm{mg}, 83 \%$ achieved HBV DNA levels of $<400$ copies $/ \mathrm{mL}$, $88 \%$ had ALT normalization, and $20 \%$ achieved HBe seroconversion. ${ }^{38}$ In a subset of patients with evaluable longterm biopsies $(n=19), 100 \%$ demonstrated improvement in Knodell necroinflammatory score, and $63 \%$ had improvement in fibrosis at year 3 . The safety profile of entecavir during long-term treatment was consistent with that observed during the phase II studies.

The entecavir-resistance program included patients from six phase II and III clinical studies. Genotypic resistance was assessed in all patients at baseline, and in patients with detectable HBV DNA ( $>300$ copies $/ \mathrm{mL}$ ) at the end of each year of therapy or during virologic breakthrough while on treatment (confirmed $\geqslant 1 \log _{10}$ increase in HBV DNA from nadir) in the worldwide entecavir phase II and III clinical trials, and the long-term rollover study. The reverse transcriptase (RT) domain of the HBV polymerase was amplified by $P C R$, and the products were directly sequenced. ${ }^{39}$ Emerging amino acid substitutions in conserved residues of the RT during entecavir treatment were tested for phenotypic resistance to entecavir. Paired samples from baseline and during breakthrough were included for phenotypic assays.

In nucleoside-naive patients, the cumulative probability of developing genotypic entecavir resistance (rtT184, rtS202, or rtM250) in the presence of lamivudine-resistance substitutions (rtM204 and rtL180M) was 1.2\% through 6 years of therapy (Fig. 6). ${ }^{40} \mathrm{~A}$ high barrier to resistance was maintained during long-term entecavir therapy in nucleosidenaive patients. This is probably due to the potent antiviral effect of entecavir; its high genetic barrier to resistance, which requires multiple mutations for resistance development; and impaired replication of the entecavir-resistance variants. During the 6-year trial, entecavir substitutions were detected in only three nucleoside-naive patients ( 3 out of 663) and one of these had pre-existing lamivudine resistance at baseline. ${ }^{40}$ In lamivudine-refractory patients, the cumulative probability of developing genotypic entecavir resistance was $57 \%$ through 6 years of therapy. A reduced barrier to resistance was observed, as the lamivudineresistance mutations required for development of entecavir resistance already existed in this population. ${ }^{40}$

The registration studies in Japan support the low rate of resistance among nucleoside-naive patients. Among those who received $0.5 \mathrm{mg}$ entecavir once daily for 3 years, the cumulative probability of entecavir resistance was $1.7 \%,{ }^{41}$ and among the lamivudine-refractory patients treated with entecavir $1.0 \mathrm{mg}$ once daily for 3 years, the cumulative probability of genotypic entecavir resistance was 33\%.42

In study AI463048, a phase IIIb study of entecavir versus adefovir in decompensated cirrhosis, entecavir demonstrated superior virologic and biochemical responses to adefovir. Entecavir was well tolerated, and the safety results were comparable between the two treatment groups. ${ }^{9}$

The safety and efficacy of entecavir in liver transplant recipients were assessed in a single-arm, open-label trial in 65 subjects with $\mathrm{CHB}$. None developed HBV viral recurrence (HBV DNA values $\geqslant 50 \mathrm{IU} / \mathrm{mL}$ ) while receiving entecavir with or without hepatitis B immunoglobulin. All evaluable subjects $(n=61)$ lost HBsAg post-transplant; 2 of these subjects experienced $\mathrm{HBsAg}$ recurrence without $\mathrm{HBV}$ viral recurrence. ${ }^{9}$

Multiple real-life studies have provided data consistent with the findings of the registration trials and the long-term rollover study in terms of efficacy, safety, and tolerability. In addition, resistance rates among nucleoside-naïve patients in real-life studies have reflected those in the registrationtrials. ${ }^{43-45}$

According to international guidelines, the goal of therapy for $\mathrm{CHB}$ is to improve quality of life and survival by preventing progression of the disease to cirrhosis, end-stage liver disease, hepatocellular carcinoma (HCC), and death. ${ }^{4-6}$ Recently, a number of real-life cohort studies have demonstrated that treatment with entecavir may reduce disease progression and the incidence of $\mathrm{HCC}$ in patients with $\mathrm{CHB} .{ }^{46-47}$ In addition, real-life studies suggest that entecavir may reduce $\mathrm{HCC}$ recurrence and survival rate in patients with $\mathrm{CHB}$ with HCC after surgical resection. ${ }^{48-50}$

\section{Conclusions}

Three key factors contributed to the success of entecavir research and development: the exploration of entecavir in various viral infections (including $\mathrm{HBV}$ ); innovative animal models which transformed the pre-clinical study of $\mathrm{HBV}$;

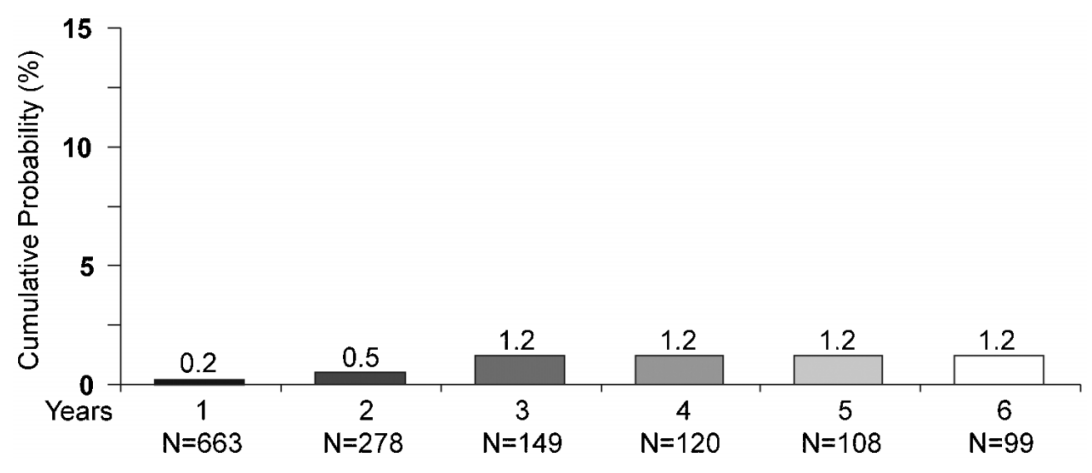

Fig. 6. Cumulative probability of entecavir resistance (rtT184, rtS202, or rtM250) in the presence of lamivudine-resistance mutations (rtM204 and rtL180M) among nucleoside-naive hepatis Be antigen ( $\mathrm{HBeAg}$ )-positive and HBeAg-negative patients during 6 years of treatment. 
multiple worldwide registration trials and separate registration studies in Japan and China, which made access to entecavir possible to people living with $\mathrm{CHB}$ not only in the Asia-Pacific region where $\mathrm{HBV}$ is endemic, but in many other countries around the world. Since the first approval of entecavir in 2005, many "real-life" cohort studies have replicated the results of the registration trials, with recent studies showing that treatment with entecavir can reduce the risk of developing hepatocellular carcinoma, and HCC recurrence following surgical resection of the tumors.

\section{Conflict of interest}

All authors are Bristol-Myers Squibb employees

\section{Author contributions}

Overall outlines of the manuscript $(\mathrm{TH})$, "Clinical development" section and overall editing of the manuscript (JG), "Discovery" section of the manuscript (SI), "Pre-clinical development" section of the manuscript (LLM), "Clinical development" section and the overall editing of the manuscript (CL).

\section{References}

[1] World Health Organization: Hepatitis B Fact Sheet No. 204. http://www. who. int/mediacentre/factsheets/fs204/en/index.html. \& http://www.who.int/ immunization/topics/hepatitis_b/en/Accessed November 2012.

[2] Müller R, Baumgarten R, Markus R, Schulz M, Wittenberg $H$, Hintsche-Kilger $B$, et al. Treatment of chronic hepatitis $B$ with interferon alfa-2b. J Hepatol 1990;11(Suppl 1):S137-S140.

[3] Deinstag JL. Hepatitis B Virus Infection. N Engl J Med 2008;359:1486-1500.

[4] Lok ASF, McMahon BJ. Chronic Hepatitis B: Update 2009. AASLD Practice Guidelines. Hepatology 2009;50:1-36.

[5] European Association for the Study of the Liver. EASL Clinical Practice Guidelines: Management of chronic hepatitis B. J Hepatol 2012;57:167-185.

[6] Liaw YF, Leung N, Guan R, Lau GK, Merican I. Asian-Pacific Consensus Working Parties on Hepatitis B. Asian-Pacific consensus statement on the management of chronic hepatitis B: a 2012 update. Hepatol Int L 2012;6: 531-561.

[7] Bisacchi GS, Chao ST, Bachard C, Daris JP, Innaimo S F, Jacobs J A, et al. BMS-200475, a novel carbocyclic 2'-deoxyguanosine analog with potent and selective anti-hepatitis B virus activity in vitro. Bioorg Med Chem Lett 1997; 7:127-132.

[8] Innaimo SF, Seifer M, Bisacchi GS, Standring DN, Zahler R, Colonno RJ. Identification of BMS-200475 as a Potent and Selective Inhibitor of Hepatitis B Virus. Antimicorb. Agents Chemother 1997;41:1444-1448.

[9] Baraclude ${ }^{\circledR}$ (entecavir) US Prescribing Information. Bristol-Myers Squibb Company. October 2012.

[10] Genovesi EV, Lamb L, Medina I, Taylor D, Seifer M, Innaimo S, et al. Efficacy of the carbocyclic 2'-deoxyguanosine nucleoside BMS-200475 in the woodchuck model of hepatitis B virus infection. Antimicrob Agents Chemother 1998;42:3209-3217.

[11] Zhou T, Saputelli J, Aldrich CE, Deslauriers M, Condreay LD, Mason WS. Emergence of drug-resistant populations of woodchuck hepatitis virus in woodchucks treated with the antiviral nucleoside lamivudine. Antimicrob Agents Chemother 1999;43:1947-1954.

[12] Zhu Y, Yamamoto T, Cullen J, Saputelli J, Aldrich CE, Miller DS, et al. Kinetics of hepadnavirus loss from the liver during inhibition of viral DNA synthesis. J Virol 2001;75:311-322.

[13] Jilbert AR, Botten JA, Miller DS, Bertram EM, Hall PM, Kotlarski J, et al. Characterization of age- and dose-related outcomes of duck hepatitis $B$ virus infection. Virology 1998;244:273-282.

[14] Marion PL, Salazar FH, Winters MA, Colonno RJ. Potent efficacy of entecavir (BMS-200475) in a duck model of hepatitis B virus replication. Antimicrob Agents Chemother 2002;46:82-88.

[15] Foster WK, Miller DS, Marion PL, Colonno RJ, Kotlarski I, Jilbert AR. Entecavir therapy combined with DNA vaccination for persistent duck hepatitis $B$ virus infection. Antimicrob Agents Chemother 2003;47:2624-2635.
[16] Julander JG, Colonno RJ, Sidwell RW, Morrey JD. Characterization of antiviral activity of entecavir in transgenic mice expressing hepatitis $B$ virus. Antiviral Res 2003;59:155-161.

[17] Yan JH, Bifano M, Olsen S, Smith RA, Zhang D, Grasela DM, et al. Entecavir pharmacokinetics, safety, and tolerability after multiple ascending doses in healthy subjects. J Clin Pharmacol 2006;46:1250-1258.

[18] Baraclude ${ }^{\circledR}$ (entecavir) European Summary of Product Characteristics, Bristol-Myers Squibb Pharma EEIG. April 2009.

[19] Bifano M, Yan JH, Xie J, Rahim S, Elefant E, Zhang D, et al. Lack of a pharmacokinetic interaction when entecavir is co-administered with lamivudine, adefovir, or tenofovir. J Hepatol 2005;42(suppl 2):171.

[20] Zhu M, Bifano M, Xu X, Wang Y, LaCreta F, Grasela D, et al. Lack of an effect of human immunodeficiency virus coinfection on the pharmacokinetics of entecavir in hepatitis B virus-infected patients. Antimicrob Agents Chemother 2008;52:2836-2841.

[21] Bifano M, Yan JH, Xie J, Zhang D, Freund J, Rahim S, et al. Hepatic impairment does not alter single-dose pharmacokinetics and safety of entecavir. Hepatology 2004;40(Suppl 1):663A.

[22] Yan JH, Bifano M Xie J, Zhang D. Grasela D, LaCreta F. Effect of age and gender on single-dose pharmacokinetics of entecavir in healthy subjects. Antivir Ther 2004; 9: H23.

[23] Lai CL, Rosmawati M, Lao J, Van Vlierberghe H, Anderson FH, Thomas N, et al. Entecavir is superior to lamivudine in reducing hepatitis B virus DNA in patients with chronic hepatitis B infection. Gastroenterology 2002;123: 1831-1838.

[24] Chang TT, Gish RG, Hadziyannis SJ, Cianciara J, Rizzetto M, Schiff ER, et al. A dose-ranging study of the efficacy and tolerability of entecavir in lamivudinerefractory chronic hepatitis B patients. Gastroenterology 2005;129:11981209.

[25] Kobashi H, Takaguchi K, Ikeda H, Yokosuka O, Moriyama M, Imazeki F, et al, Efficacy and safety of entecavir in nucleoside-naive, chronic hepatitis B patients: phase II clinical study in Japan. J Gastroenterol Hepatol 2009;24: 255-261.

[26] Chang TT, Gish RG, de Man R, Gadano A, Sollano J, Chao YC, et al. A comparison of entecavir and lamivudine for HBeAg-positive chronic hepatitis B. N Engl J Med 2006;354:1001-1010.

[27] Gish RG, Lok AS, Chang TT, de Man RA, Gadano A, Sollano J, et al. Entecavir Therapy for up to 96 Weeks in Patients With HBeAg-Positive Chronic Hepatitis B. Gastroenterology 2007;133:1437-1444.

[28] Lai CL, Shouval D, Lok AS, Chang $T$, Cheinquer $H$, Goodman $Z$, et al. Entecavir versus lamivudine for patients with $\mathrm{HBeAg}$-negative chronic hepatitis B. N Engl J Med 2006;354:1011-1020.

[29] Sherman M, Yurdaydin C, Sollano J, Silva M, Liaw YF, Cianciara J, et al. Entecavir for treatment of lamivudine-refractory, HBeAg-positive chronic hepatitis B. Gastroenterology 2006;130:2039-2049.

[30] Han SH, Chang TT, Chao YC, Yoon SK, Gish RG, Cheinquer H, et al. Five years of continuous entecavir for nucleoside-naive $\mathrm{HBeAg}(+)$ chronic hepatitis $\mathrm{B}$ : results from study ETV-901. Hepatology 2008;48(Suppl 1):705A-706A.

[31] Schiff ER, Lee SS, Chao YC, Kew Yoon S, Bessone F, Wu SS, et al. Long-term treatment with entecavir induces reversal of advanced fibrosis or cirrhosis in patients with chronic hepatitis B. Clin Gastroenterol Hepatol 2011;9:274276.

[32] Manns MP, Akarca US, Chang TT, Sievert W, Yoon SK, Tsai N, et al. Long-term safety and tolerability of entecavir in patients with chronic hepatitis $B$ in the rollover study ETV-901. Expert Opin Drug Saf 2012;11:361-368.

[33] Yao G, Chen C, Lu W, Ren H, Tan D, Wang Y, et al. Efficacy and safety of entecavir compared with lamivudine in nucleoside-naïve patients with chronic hepatitis B: a randomized double-blind trial in China. Hepatol Int 2007; 1:365-372.

[34] Yao G, Chen CW, Lu WL, Ren H, Tan DM, Wang YM, et al. Two-year results from a phase 3 study in nucleoside-naïve patients in China (ETV-023). Hepatol Int 2007;1:124.

[35] Yao G, Zhou X, Xu D, Wang B, Ren H, Liu J, et al. Entecavir for the treatment of lamivudine-refractory chronic hepatitis B patients in China. Hepatol Int 2007; $1: 373-381$.

[36] Suzuki F, Toyoda J, Katano Y, Sata M, Moriyama M, Imazeki F, et al. Efficacy and safety of entecavir in lamivudine-refractory patients with chronic hepatitis B: randomized controlled trial in Japanese patients. J Gastroenterol. Hepatol 2008;23:1320-1326.

[37] Shindo M, Chayama K, Mochida S, Toyota J, Tomita E, Kumada H, et al. Investigation of the antiviral activity, dose-response relationship and safety of entecavir following 24-week oral dosing in nucleoside-naive adult patients with chronic hepatitis B: a randomized double-blind Phase II clinical trial in Japanese patients. Hepatol Int 2009;3:445-452.

[38] Yokosuka O, Takaguchi K, Fujioka S, Shindo M, Chayama K, Kobashi H, et al, Long-term use of entecavir in nucleoside-naive Japanese patients with chronic hepatitis B infection. J Hepatol 2010;52:791-799.

[39] Tenney DJ, Levine SM, Rose RE, Walsh AW, Weinheimer SP, Discotto L, et al. Clinical emergence of entecavir-resistant hepatitis $B$ virus requires additional 
substitutions in virus already resistant to lamivudine. Antimicrob Agents Chemother 2004;48:3498-3507.

[40] Tenney DJ, Pokornowski KA, Rose RE, Baldick CJ, Eggers BJ, Fang J, et al. Entecavir maintains a high genetic barrier to HBV resistance through 6 years in naïve patients. J Hepatol 2009;50(Suppl 1):S10.

[41] Yokosuka O, Kumada H, Toyota J, Takaguchi K, Kobashi H, Shindo M, et al. Three-year assessment of entecavir resistance in nucleoside-naïve and lamivudine-refractory Japanese patients with chronic hepatitis B. Hepatol Int 2008;2:A161.

[42] Izumi N, Kumada H, Toyota J, Yokosuka O, Kobashi H, Shindo M, et al. Efficacy and safety of 3 years treatment with entecavir in lamivudinerefractory Japanese chronic hepatitis B patients. Hepatol Int 2008;2:A186.

[43] Zoutendijk R, Reijnders JG, Brown A, Zoulim F, Mutimer D, Deterding K, et al. Entecavir treatment for chronic hepatitis $B$ : adaptation is not needed for the majority of naïve patients with a partial virological response. Hepatology 2011;54:443-451.

[44] Seto WK, Lai CL, Fung J, Wong DK, Yuen JC, Hung IF, et al. Significance of HBV DNA levels at 12 weeks of telbivudine treatment and the 3 years treatment outcome. J Hepatol 2011;55:522-528.
[45] Pol S, Lampertico P. First-line treatment of chronic hepatitis B with entecavir or tenofovir in 'real-life' settings: from clinical trials to clinical practice. J Viral Hepat 2012;19:377-386.

[46] Hosaka T, Suzuki F, Kobayashi M, Seko Y, Kawamura Y, Sezaki H, et al. Longterm entecavir treatment reduces hepatocellular carcinoma incidence in patients with hepatitis B virus infection. Hepatology 2013;58:98-107.

[47] Zoutendijk R, Reijnders JG, Zoulim F, Brown A, Mutimer DJ, Deterding K, et al. Virological response to entecair is associated with a better clinical outcome in chronic hepatitis B patients with cirrhosis. Gut 2013;62:760-765.

[48] Komorizono Y, Sako K, Nakaya M, Shibatou T. Impact of nucleoside analog entecavir on survival of patients with hepatitis B virus-related hepatocellular carcinoma. DDW 2012; presentation 464.

[49] Lee DH, Lee JH, Cho Y, Lee YB, Cho EJ, Yu SJ, et al. Entecavir treatment significantly reduces the risk of hepatocellular carcinoma recurrence in patients with chronic hepatitis B. AASLD 2012; abstract \#367.

[50] Wu CY, Chen Y], Ho HJ, Hsu YC, Kuo KN, Wu MS, et al. Association between nucleoside analogues and risk of hepatitis $\mathrm{B}$ virus-related hepatocellular carcinoma recurrence following liver resection. JAMA 2012;308: 1906-1914. 